\title{
La mediación de Moisés: autoridad e historia
}

\author{
Andrés Ferrada
}

aferradm@uc.cl

\section{INTRODUCCIÓN}

Hoy nos reúne la inauguración oficial del año académico en nuestra facultad, en el contexto del Año de la $\mathrm{Fe}$, que está viviendo la Iglesia Universal. Nuestra Universidad impulsa esta iniciativa pastoral en la Iglesia diocesana por especial encargo de nuestro pastor, monseñor Ricardo Ezzati. Nos congrega la esperanza puesta por la Iglesia en nuestro trabajo, entendido como apostolado intelectual y, por lo mismo, fuente de evangelización, promoción humana y cultura cristiana para nuestra sociedad. Además, la sucesión de Benedicto XVI al Papa Francisco, primer sucesor de Pedro venido de Latinoamérica, acrecienta esta esperanza, pues los gestos de bondad y humildad evangélicas de ambos pontífices han sido para "el mundo y en la Iglesia un resquicio de luz en medio de tantas nubes"1.

\footnotetext{
De la homilía del Papa Francisco en la Misa de inauguración de su ministerio petrino, 19 de marzo de 2013.
}

Sin duda, en esta sucesión la Iglesia se ha mostrado maestra de humanidad y de sabiduría. Algo así como una feliz sinfonía entre el "no anteponer nada a Cristo" de san Benito -Benedicto- y el "Francisco, restaura mi Iglesia" del Crucificado al poverello de Asís.

Resulta más que evidente que a esta circunstancia eclesial se unen tantas otras que están viviendo los distintos actores de esta comunidad educativa: administrativos, estudiantes, profesores y directivos; y no solo a nivel profesional, sino también en los amplios aspectos de la vida humana. Y todo ello referido especialmente a la relación con el Señor, la cual nos constituye en creyentes, miembros de su Iglesia y discípulos misioneros al servicio del mundo.

Esta ponencia tiene por título: "La mediación de Moisés: autoridad e historia", pues a través de la consideración de la misión de Moisés como mediador entre 
Dios y el pueblo, según se describe en el Pentateuco,pretendo poner a la luz un rasgo esencial de la fe judeocristiana: la autoridad de sus transmisores sobre el pueblo creyente en el aquí y ahora de las circunstancias concretas espaciotemporales y, por tanto, la historia como lugar del diálogo de la salvación.

El Sínodo de los Obispos celebrado en Roma en octubre pasado, según reza su título, "La nueva evangelización para la trasmisión de la fe", tuvo por foco central la renovación eclesial necesaria para que la comunidad creyente realice en el mundo actual la finalidad de su existencia: "La Iglesia existe para evangelizar" ${ }^{2}$, naturalmente en la circularidad vital de predicación, fe y Palabra de Cristo según la lúcida exposición de san Pablo en $\mathrm{Rm} 10,1$ 0-17, cuyo corolario sintetiza esta imbricación: "La fe viene de la predicación, y la predicación, por la Palabra de Cristo"3. Pero para que el organismo eclesial funcione con esta vitalidad se requiere del envío de los predicadores dotados de autoridad. El apóstol de los gentiles lo dice sin ambages en la última de las preguntas retóricas concatenadas, con la que también culmina su des-

\footnotetext{
$2 \quad$ Cf. EN 14.

3 Rm 10, 17.
}

cripción de la circularidad de la evangelización: «¿Cómo predicarán si no son enviados?”"

El mandato divino, dado al predicador para que preste su servicio, constituye el reconocimiento público y eclesial de la autoridad de la que está revestido en sus funciones. Comúnmente en las Escrituras se explicita que dicha autoridad proviene de Dios mismo. El género literario usado para hacerlo varía de obra en obra. Los más comunes son el relato de vocación ${ }^{5}$, el natalicio extraordinario $^{6}$, la misión apostólica ${ }^{7}$ y/o la rúbrica sacra del libro ${ }^{8}$.

Surge inmediatamente la pregunta: ¿por qué los autores bíblicos deben enfatizar que es sagrada la autoridad de los predicadores y, por ende, de los libros donde se contienen sus testimonios? La respuesta es obvia: la potestad de esos personajes había sido rebatida, incluso fuertemente cuestionada. $\mathrm{Su}$ cede que los predicadores son mediadores del mensaje divino para

Rm 10, 14-15.

5 Cf., por ejemplo, la vocación profética: Ex 3, 1-4, 18; 1Sam 3, 1-21; Am 7, 1017 ; Is 6, 1-13; Jr 1, 4-10.

6 Cf., por ejemplo, Ex 2, 1-10; 1Sam 1, 1928; Mt 1, 1 8-25; Lc 1, 26-38; 2, 1-20.

7 Cf., por ejemplo, Mt 20, 16-20; Mc 16, 15-18; Lc 24, 44-49; Ap 1, 17-20.

8 Cf., por ejemplo, Dt 4, 1-2; Lc 1, 1-4; Jn 20, 30-31; Ap 22, 18-19. 
su pueblo, aunque incluso también para otros pueblos o para todo el género humano. La autoridad del mediador dice relación precisamente con el reconocimiento del carácter vinculante de las palabras que transmite no como propias, sino como provenientes de Dios. La comunidad creyente percibe la auto-manifestación divina a través de un determinado predicador y lo refrenda en el escrito que contiene su predicación con alguno de los géneros literarios antes citados. En otras palabras, los hagiógrafos, bajo la inspiración divina, han debido usar estos recursos literarios principalmente cuando enfrentaban serias dificultades para que las comunidades, destinatarias de sus escritos, recibieran el mensaje trasmitido como "Palabra de Dios" por mediadores dotados de autoridad-fueran ellos mismos o los testigos a cuya misión hacen referencia- ${ }^{9}$. Esta dificultad de recepción nos pone frente a las circunstancias histórico-contextuales de las comunidades destinatarias, pues los escritos bíblicos en su inmensa mayoría intentan constituirlas o refundarlas como el auténtico pueblo de Dios o una determinada porción de él. Evidentemente,

9 La cuestión se hace muy evidente en algunos escritos bíblicos como, por ejemplo, en las cartas paulinas: cf. 1Co 14, 36; 2Co 2, 17 en contraste con 1Ts 2, 13. lo hacen ante la amenaza de otras predicaciones, incluso por escrito, que ellos mismos comprenden como deformación de la identidad del pueblo creyente. El énfasis puesto en la autoridad divina de la cual está premunido el predicador y los escritos donde se consignan sus enseñanzas, persigue precisamente acentuar este rasgo.

$\mathrm{Al}$ aproximarnos a los escritos bíblicos debemos, por tanto, perder la ingenuidad de entender la inspiración como un dictado de un grácil ser angélico al oído de un ascético escritor; la inspiración del Espíritu Santo -entendida como el carisma concedido a ciertas personas para poner por escrito la "Palabra de Dios" - ha corrido en medio de discusiones, disensiones y violencias de todo género. Los hagiógrafos han tomado parte en ese proceso vital más o menos largo con posturas a veces claras; otras, algo vacilantes, usando de sus capacidades y habilidades humanas. Al final, han puesto por escrito solo y todo lo que Dios quería” ${ }^{10}$.

Pero la autoridad de un escrito dice relación también con la historia, más específicamente con la consecución, consolidación o subversión de un orden social y político. Detrás de cada discurso se

10 Cf. DV 11. 
deja ver la necesidad de quienes lo componen de afirmar su autoridad. Recurramos a ejemplos del ámbito político: Felipe II gustaba decir que sus dominios eran un "imperio donde jamás se ponía el sol" y/o denominar a su armada "la invencible". Y una y otra cosa era parte de un discurso por medio del cual la monarquía española necesitaba asentar su poder, pues ciertamente era cuestionada o le disputaban su autoridad, interna y externamente. Por cierto, la postura del primer y único rey de Chile -otro título que se inserta en el mismo juego ideológico- era más recatada que la de su bisnieto Luis XIV de Francia, el "rey sol", quien, un siglo más tarde, no solo atribuía a su reino el poder, sino también lo identificaba consigo mismo, en cuanto nación organizada: "L'État, c'est moi”. En discursos como estos queda de manifiesto el poder y la debilidad de sus emisores. No es el momento de mostrar cómo las frases recién citadas manifiestan la relación entre ambos extremos en sendas experiencias políticas de los tiempos modernos. Sin embargo, ellas ilustran una realidad constante en la historia de la literatura: no pocas veces los escritos buscan afianzar la autoridad cuestionada o disputada.

Esta función literaria es muy relevante en la Biblia. En efecto, en ella se dan cita y coordinan los escritos fundamentales de un pueblo débil y severamente amenazado en su existencia histórica como nación. Posteriormente, también en el Nuevo Testamento, los textos de una comunidad religiosa casi insignificante desde el punto de vista sociológico, que se entiende paradójicamente como un pueblo presente $-y$ que es al mismo tiempo fermento de vida- en medio de todas las naciones y, por lo mismo, trascendente a todas ellas. Sin duda, en las Sagradas Escrituras el afianzamiento y/o justificación de la autoridad intenta también consolidar unas determinadas experiencias sociopolíticas, para lo cual recurre -como es habitual en la literatura antigua (aunque no solo en ella) - al designio divino. En particular, pretende ofrecer a los destinatarios la seguridad de que las palabras pronunciadas por las autoridades del pueblo provienen de Dios mismo, aunque se presenten en el humilde ropaje de la palabra humana.

Para ilustrar esta realidad, quisiera detenerme, en esta oportunidad, en uno de los discursos más significativos para la autocomprensión de Israel como pueblo de Dios: la estipulación de la Alianza del Sinaí en Ex 19-24. En este texto se percibe nítidamente la intención de los escribas que le 
dieron su forma final de justificar la autoridad de Moisés en relación a la transmisión de la Ley. Los destinatarios del relato tienen la seguridad que todos y cada uno de los elementos que componen el discurso de Moisés son palabra divina. Con todo, es evidente que él es un personaje del pasado, pero sucedido en su función de mediador por instituciones en el aquí y ahora, Sacerdotes y Ancianos que pervivieron como estamentos al desastre de la descomposición social provocada por la destrucción de Jerusalén a manos de los babilonios al inicio del siglo VI a. C. Muchos de los cuales fueron desterrados, pero que vueltos a la patria, configuraron un nuevo Israel ya no fundado en el poder de un rey dentro de un ámbito geográfico propio. Para base de esa nueva sociedad, junto con el culto en el santuario renovado, fueron conformando los cinco "quintos" que constituyen la Ley de Moisés.

¿Por qué en los "cinco quintos de la Ley" se hizo necesario este esfuerzo literario? Para despejar esta interrogante, primero aludiremos a la autoridad del Pentateuco en relación a las otras unidades literarias de la Biblia hebrea; después contemplaremos en líneas generales la autoridad de Moisés en su biografía y, luego, nos detendremos a considerarla en el momento más sublime de su vida: la estipulación de la Alianza del Sinaí (Ex 19-24).

a) LA AUTORIDAD DE MoIsÉS EN EL LIBRo DEL ÉxOdo Y EN EL Pentateuco

El estudio de la disposición canónica de la Biblia Hebrea (Tanak) ha puesto en evidencia que la Torá es su cuerpo literario fundamental. En efecto, en esta disposición la Torá tiene un lugar único en las Escrituras $^{11}$. A ella debe someterse Josué para alcanzar éxito en su misión (cf. Jos 1, 7-8), y así también todos los profetas. Malaquías finaliza la profecía precisamente llamando al recuerdo de la Ley de Moisés (cf. Ml 3, 22-24). En evocarla consiste el ministerio de todo profeta. La Torá es también fuente de sabiduría para Israel y su cumplimiento es el criterio de juicio (cf. Sl 1, 2.5-6). La posición única de la Torá está expresamente vinculada a Moisés, como queda de manifiesto en los puntos neurálgicos de la disposición canónica de la Biblia Hebrea a los que hemos aludido. El texto fundamen-

11 Cf. E. Zenger, Einleitung in das AlteTestament, 24-26 y la recepción de esta teoría en J.-L.SKA, Introducción a la lectura del Pentateuco. Claves para la interpretación de los cinco primeros libros de la Biblia, 23-31. 
tal es precisamente su final, Dt 34. 10-12:

Nunca más surgió en Israel otro profeta semejante a Moisés -con quien el Señor hablaba cara a cara- ya sea por todas las señales y prodigios que el Señor le mandó realizar en Egipto contra el Faraón, contra todos sus servidores y contra todo su país, ya sea por la gran fuerza y el terrible poder que él manifestó en presencia de todo Israel.

A la hora de su muerte, Moisés es presentado como el más grande de los profetas en razón de la inmediatez en la comunicación con el Señor ${ }^{12}$ y de la naturaleza del todo excepcional de su misión ante el faraón y ante Israel. Esta indicación cierra la Torá aportando un criterio hermenéutico fundamental: la supremacía que ocupa en la Tanak. El lector atento comprende que su superioridad se corresponde con la inmediatez de revelación del mensaje de los textos que se contienen ella. Los otros dos cuerpos literarios, por tanto, son de nivel inferior, como de hecho lo atestiguan los inicios y finales de los Nebiim y de los Ketubim $^{13}$ y muchos otros textos intermedios dentro de esas unida-

12 Cf. Ex 33, 11; Nm 12, 6-8.

13 Cf. Jos 1, 1-8; Ml 3, 22-24; Sl 1 y 2Cr 36, 22-23. des literarias ${ }^{14}$. Además, todos estos textos, de una u otra manera, muestran la supeditación a la Torá, como acabamos de mencionar.

Ahora bien, como se insinúa más arriba, la Torá tiene por finalidad fundar la existencia del pueblo de Dios; en concreto mostrar quién pertenece a él; es decir, quién es depositario de las promesas divinas. Su ámbito vital es la Alianza entre el Señor e Israel (cf. Ex 19-24; 32-34; Dt 5-11; $12-$ 26), la cual supone una relación muy estrecha entre ambos ${ }^{15}$ descrita algunas veces con la metáfora nupcial ${ }^{16}$; otras, con la evocación de la relación paterno-filial ${ }^{17}$. De hecho, una vinculación así caracterizaba los pactos entre los pueblos del Medio Oriente Antiguo, por los cuales los contrayentes se obligaban entre sí, invocando sus nombres y las relaciones mu-

14 Son muchos los textos proféticos donde claramente la profecía se revela como la actualización de la Ley. Cf., p. ej., 1Re 2, 1-4; $2 \operatorname{Re} 21,8-12$; Am 2, 4-8; Is 42, 20 25; Jr 6, 19-23; Ez 22, 26-31. También numerosos pasajes de los Otros Escritos remarcan el valor que tiene la Torá como orientadora indispensable de la conducta humana. Cf., p. ej., Dn 9, 9-13; Ne 1, 7-11; Ne 10, 28-30; Sl 40, 7-11; Sl 89, 28-33; Pr 28, 4-9.

15 Cf., por ejemplo, Ex 19, 5-6; Dt 10, 14-15.

16 Cf., por ejemplo, Jr 2, 1-9; Os 2, 4-25; Ez 16, 8-14.

17 Cf., por ejemplo, 2Sam 7, 13-14 // 1Cro 28, 6-8; Os 11, 1-3; Ez 16, 1-7. 
tuas de amor y parentesco que los unían $^{18}$.

\section{b) La autoridad de Moisés eN SU BIOGRAFÍA}

La autoridad de Moisés proviene del Señor. Esta es la afirmación fundamental que los escribas que dieron la forma actual al Pentateuco, quisieron infundir en la historia de Moisés, la cual se confunde con la constitución del pueblo ${ }^{19}$. Lo hicieron dramáticamente de dos formas coordinadas: narrando su nacimiento y su vocación profética. El primero bajo el prisma del salvador salvado; la segunda, usando el género literario de un modo del todo particular.

Ex 1-2 ${ }^{20}$ describen el nacimiento de Moisés en el contexto de amenaza de subsistencia para los

18 Para la comparación entre las alianzas veterotestamentarias y los tratados de vasallaje del Medio Oriente Antiguo: D.J. McCARthy, Treaty and Covenant. A Study in Form in the Ancient Oriental Documents and in the Old Testament, AnBib 21A, Rome 1978. Cf. también G.E. MendenHALl, "Covenant Forms in Israelite Tradition”, BA 17 (1954) 50-76 = Law and Convenant in the Ancient Near East, Pittsburgh 1955; J. Muilenburg, "The Form and Structure of the Covenantal Formulations", VT 9 (1959) 347-365.

19 Cf. J. Blenkinsopp, El Pentateuco, 76.

20 Para el estudio de estos capítulos véase A. Ferrada Moreira, El nacimiento de Moisés. Historia y teología, con bibliografía especializada. descendientes de Jacob. Ellos inocentemente han caído en desgracia ante sus anfitriones egipcios, quienes intentan aniquilarlos pues los experimentan, a su vez, paradójicamente como una amenaza (cf. Ex 1, 9). Al mismo tiempo, los quieren retener como esclavos para dedicarlos a la construcción de grandes obras (cf. Ex 1, 10). Sin duda, la biografía de Moisés comienza con una contradicción que desde el inicio delata la naturaleza compuesta de la unidad literaria desde el punto de vista diacrónico.

En este panorama poco esperanzador, Dios interviene por medio de agentes que disciernen, en las realidades seculares, la voluntad divina. En concreto, perciben el valor y el respeto a la vida como eje central de la conducta huma$\mathrm{na}^{21}$ : las parteras y la princesa no cumplen el nefasto plan de exterminio del malvado faraón ${ }^{22}$. La iniciativa divina por la salvación del niño, queda de manifiesto claramente si se tiene en cuenta que se usa el motivo folclórico ancestral del expósito, misteriosamente salvado por la divinidad ${ }^{23}$. El

21 Cf. A. Ferrada Moreira, "Vida humana $y$ conciencia en Ex. 1.15-2-10. Un aporte desde la teología bíblica del A.T. a la discusión sobre el respeto a la vida humana".

22 Cf. Ex 1, 15-21; 2, 1-10.

23 Cf. J. Conen, The Origins and Evolution of the Moses Nativity Story, D.B. RedFord, 
recién nacido Moisés, como muchos otros personajes, es objeto de una asombrosa salvación. Esta circunstancia presagia su destino como caudillo de Israel. Así, no faltan los comentadores que se esfuerzan en leer la narración de la salvación de Moisés de las aguas, como una prolepsis de la salvación de los demás descendientes de Jacob en el mar Rojo. La etimología popular, puesta en boca de la princesa egipcia, refuerza esta idea. En efecto, el autor sagrado vincula al nombre del personaje con el hecho extraordinario de su rescate de las aguas ${ }^{24}$. Es así como el salvador del pueblo debe ser considerado siempre como el primer salvado, gracias a la intervención extraordinaria del Señor, aunque en circunstancias aparentemente mundanas. Esa apariencia, sin embargo, se resuelve en Providencia divina. En efecto, para el lector, que lee cada pieza de esta sección del libro como parte de un todo, no hay detalles banales, como tal vez en la vida cotidiana.

"The Literary Motif of the Exposed Child (cf. Ex. ii 1-10)".

24 Cf. R.E. Longacre, "Discourse Perspective", 178-181. Otros casos similares se verifican en el relato del nacimiento de los hijos de Jacob: Gn 29, 32. 33. 34. 35; 30, 6. 8. 11. 13. 18. 20. 23. 24. Los ejs. más significativos son Gn 29, 32. 33: como en Ex 2, 10, introducen el discurso con la partícula Kî̀; cf. Gesenius, 157b; Joüon, 157c.
Ex 3-4, concatenados con lo anterior, continúan la narración del joven Moisés, prófugo y, por lo mismo, pastor por necesidad ${ }^{25}$. Además de esta circunstancia, su figura algo bucólica entraña otra perspectiva: la frustración de su primera incursión como líder de sus con nacionales. En efecto, después de las primeras escaramuzas, "sus hermanos" no le reconocen autoridad alguna sobre ellos: “¿Quién te nombró juez y árbitro sobre nosotros?" (Ex 2, 14). Persecución y rechazo son dos líneas que continuarán a lo largo de toda la vida de Moisés; desde un punto de vista negativo, evidentemente, deben ser interpretadas como intentos reiterados de poner a la luz la fuente de la autoridad del personaje, esto es: su origen no está en él mismo; Moisés no se abroga ser juez y pastor de su pueblo.

Precisamente, a esa misma conclusión conduce la narración del llamado de Moisés, ahora en clave positiva. El lector atento descubre que la narración usa la estereotipia de la vocación, especialmente del profeta ${ }^{26}$. Este género literario incluye varios elementos, entre los cuales destaca la objeción del

\footnotetext{
25 Cf. Ex 2, 11-15a.

26 Sigo a J. L., SKA, La vocazione di Mosè, Esodo 3, 1-4, 18, 19-25, con amplia bibliografía en las obras clásicas que abordan el argumento.
} 
llamado, ante el encargo que se le asigna. La tensión es resuelta por los argumentos divinos y/o de sus mensajeros. La finalidad de este rasgo es diáfana: narrativamente, persuade al personaje de que es capaz de cumplir la tarea encomendada, por más difícil que ella parezca, e intenta convencer a los que recibirán las profecías (o los efectos de otros encargos) de la autenticidad de la vocación del enviado $^{27}$. Desde el punto de vista retórico-pragmático, este último propósito se extiende a los destinatarios del relato, ciertamente la comunidad israelita post-exílica que está detrás de la forma actual del Pentateuco.

Ahora bien, en el caso de la vocación de Moisés encontramos que la objeción y dicha superación por parte del Señor se multiplican por cinco $^{28}$. Esta abundancia enfatiza sobre manera el origen divino de la autoridad del mediador. Entre esas cinco objeciones, algunas desarrollan el tema del cuestionamiento de la autoridad, tanto por parte de quienes detentan el poder en la historia, como en el seno de la comunidad creyente destinataria del relato (por qué no decir

27 Cf., p. ej., Am 7, 14-15; Is 6, 8-9; Jr 1, 5-8.

28 J. L. SKA, La vocazione..., 27-28 estructura Ex 3, 1-4, 18 a base de las objeciones de Moisés: también, entre nosotros mismos sus receptores del siglo XXI).

La autoridad de Moisés es debatida durante toda su vida y, al mismo tiempo, las narraciones del Pentateuco porfían en señalar que es Dios quien lo reviste de poder sagrado. Pero no solo eso, sino también que rechazarlo significa oponerse al Señor. Lo hacen de variadas formas. Por ejemplo: ante la incredulidad y la murmuración del pueblo por falta de agua en el desierto, con el portento del manantial que brota de la roca ${ }^{29}$; ante el hambre sufrida en ese mismo lugar, con el maná y las codornices ${ }^{30}$; ante la desesperación de los israelitas frente a la aparente ausencia

\begin{tabular}{|c|c|}
\hline Dios ENVÍA & MOISÉS RESPONDE \\
\hline $\begin{array}{l}\text { (1) Visión y Misión: } \\
\text { "Ve" }(3,1-10) \\
\text { (a) 3,1-6: visión de } \\
\text { la zarza ardiente } \\
\text { (b) } 3,7-10: \text { misión y } \\
\text { su fundamento }\end{array}$ & $\begin{array}{l}\text { (2) Primera serie de } \\
\text { objeciones de Moisés y } \\
\text { respuestas de Dios (3, } \\
11-15) \\
\text { (a) } 3,11-12 \text { : ¿quién soy yo } \\
\text { para ir...? } \\
\text { (b) } 3,13-15 \text { : ¿cuál es su } \\
\text { nombre? }\end{array}$ \\
\hline $\begin{array}{l}\text { (3) Pormenores de la } \\
\text { misión: "Ve" (3, } \\
\text { 16-22) } \\
\text { (a) 3,16-17: misión } \\
\text { ante los ancianos } \\
\text { (b) } 3,18 \text { : misión } \\
\text { ante el faraón } \\
\text { (c) } 3,19-20 \text { : } \\
\text { dificultades en la } \\
\text { misión } \\
\text { (d) } 3,21-22 \text { : } \\
\text { expoliación de los } \\
\text { egipcios }\end{array}$ & $\begin{array}{l}\text { (4) Segunda serie de } \\
\text { objeciones de Moisés y } \\
\text { respuestas de Dios (4, } \\
1-17) \\
\text { (a) } 4,1-9: \text { ¿cómo me } \\
\text { creerán? } \\
\text { (b) } 4,10-12: \text { no sé hablar } \\
\text { (v.12: "Ve") } \\
\text { (c) } 4,13-17: \text { manda a otro, } \\
\text { menos a mí }\end{array}$ \\
\hline \multicolumn{2}{|c|}{ (5) Conclusión: Moisés "fue” $(4,18)$} \\
\hline $\begin{array}{l}{ }_{29} \text { Cf. Ex 17, 1-7; } \\
30 \text { Cf. Ex 16; Nm }\end{array}$ & 13. \\
\hline
\end{tabular}


divina, con la peste o la espada ${ }^{31}$. Otro modo de recalcar lo mismo es el castigo para quienes pretenden sustituir a Moisés o desafían las prescripciones trasmitidas por él: María y Aarón ${ }^{32}$; Nadab y Abihứ ${ }^{33}$; en sentido análogo, aunque no referido explícitamente a Moisés, deben entenderse los oráculos de Balaán ${ }^{34}$, quien encargado de maldecir a Israel, fue salvado del castigo por su muy terca, aunque sagaz, burra.

Si la huida ante la persecución del faraón pone en evidencia que Moisés carece de toda autoridad entre los de su raza; las respuestas divinas a sus objeciones, que ahora como simple pastor de ovejas plantea en el desierto, subrayan que es el Señor la fuente de donde brota su autoridad. Y no solo eso, sino también que es Dios quien lo ha previsto todo, y con detalle, ya que en sus respuestas incluye un exhaustivo programa de la liberación de los israelitas ${ }^{35}$. En efecto, en esa prolepsis se predice el rechazo de Moisés, aunque solo por parte de los egipcios: "Sé que el rey de Egipto no los deja-

31 Cf. Ex 32, 1-6. 25-35; Nm 14, 20-38.

32 Cf. Nm 12.

33 Cf. Lv. 10, 1-3.

$34 \mathrm{Nm}$ 22-24, especialmente 22, 22-35.

35 Cf. Ex 3, 16-22. rá salir sino forzadamente" ${ }^{36}$. Con todo, acto seguido, presagia también la incredulidad de los israelitas y plasma su tercera objeción: "No van a creerme, ni escucharán mi voz; dirán: El Señor no se te apareció" 37 . El cumplimiento de estos particulares y otros anuncios en ese mismo discurso divino son narrados en el relato de la liberación de los israelitas esclavizados, en Ex 4, 19-15, 22, y se prolongan en el resto de la gesta constitutiva del pueblo en el libro del Éxodo y en los demás libros del Pentateuco. Incluso, y pese al elogio a Moisés con ocasión del relato de su muerte en Dt 34, 1-12, un poco antes de ese lugar, duramente el Señor recrimina al líder de Israel:

Por haberme sido infiel en medio de los israelitas, en las aguas de Meribá Cadés, en el desierto de Sin, por no haber manifestado mi santidad en medio de ellos, por eso, solo de lejos verás la tierra, sin entrar en ella, en la tierra que estoy por dar a los israelitas ${ }^{38}$.

Moisés había cedido a la presión de la incredulidad de los suyos en Cadés. En efecto, los israelitas no confiaron en el Señor vacilando tomar posesión de la tierra prometida, pues dieron

\footnotetext{
36 Cf. Ex 3, 19.

37 Ex 4, 1.

38 Dt 32, 51-52; cf. 1, 19-45;3, 23-28.
} 
crédito a los espeluznantes relatos de la mayoría de los exploradores que habían enviado. La dramática muerte de Moisés fuera de la tierra prometida, en definitiva, fue causada por el defectuoso modo con que ejerció la autoridad de la que estaba revestido en aquella crucial circunstancia.

En Ex 14 encontramos precisamente lo contrario: el ejercicio del poder en plena sintonía con el Señor. En efecto, Moisés se sobrepone ante los miedos y las murmuraciones del pueblo, llevados al colmo cuando sugiere incluso invertir la gesta salvadora del Señor, “...preferimos servir a los egipcios que morir en el desierto" 39 . Pero Moisés logra que sus connacionales venzan la prueba, infundiéndoles ánimo para dejarse sorprender por las maravillas divinas obradas a su favor. Al final, los israelitas se llenan de temor del Señor y no pueden sino reconocerlo, creer en él, pero además manifiestan su adhesión a Moisés: "Y al percibir Israel el gran poder que el Señor había ejecutado contra los egipcios, temió el pueblo al Señor, y creyeron en el Señor y en Moisés" ${ }^{40}$. Creer en el Señor trae aparejado creer en su mediador, pues de hecho la liberación de Israel es obra

\footnotetext{
39 Cf. Ex 14, 11-14.

$40 \quad$ Ex 14, 31.
}

exclusiva del Señor, quien la ha realizado contando con el servicio de Moisés.

¿Por qué asociar la fe en el Señor con la fe en su siervo? Dicho de otro modo, ¿por qué hay necesidad de una mediación con autoridad?

La respuesta sin duda se iluminará si contemplamos el momento sublime de la vida de Moisés según se narra en el Pentateuco, cuando Israel comienza a existir como pueblo del Señor.

c) La autoridad de Moisés en LA CONSTITUCión DEL PUEBLO DE ISRAEL

La constitución de Israel como pueblo del Señor es descrita en la perícopa del Sinaí ${ }^{41}$. Un texto complejísimo y fascinante. Para iluminar la interrogante que acabamos de formular, nos detendremos, con algo de calma aunque brevemente, solo en el comentario de Ex 20, 18-21 ${ }^{42}$ :

${ }^{18}$ Todo el pueblo percibía los truenos, los relámpagos, el resonar de la trompeta y el monte que humeaba; temblando se mantenían a distancia. ${ }^{19} \mathrm{En}$ -

Cf. Ex 19-24

42 Cf. B.S. Childs, The Book of Exodus. A Critical, Theological Commentary, 371373; C. Dohmen, Exodus, 87-88. 128132; J.I. Durham, Exodus, 301-305. 
tonces, dijeron a Moisés: «Háblanos tú y te escucharemos, pero que no hable Dios directamente con nosotros no sea que muramos». ${ }^{20}$ Moisés respondió al pueblo: «No teman porque Dios ha venido para probarlos y para que lo teman a fin de que no pequen». ${ }^{21} \mathrm{El}$ pueblo se mantenía a distancia mientras Moisés se acercaba a la densa nube donde Dios estaba.

Observemos primero algunas notas desde el análisis narrativo:

El relato constituye un claro momento escénico en la narración de la Perícopa del Sinaí, porque después del largo discurso divino del Decálogo, reaparece en escena el pueblo y cambia la temática. En efecto, Ex 20, 18-21 aparentemente no dice relación directa con el Decálogo, al menos con su contenido $^{43}$.

43 Si se compara el pasaje con Dt 5, 2425 se detectan los siguientes elementos comunes. La misma estructura narrativa; el discurso de Moisés: el pueblo se recuerda de los acontecimientos en el Sinaí, recapitulación de acontecimientos acaecidos en la montaña de Dios. En Dt 5, 31, Moisés permanece en la montaña. En Dt Gss son especificados los mandamientos (Código Deuteronómico), las cuales toman el lugar del Código de la Alianza de Ex 21-23. Ambos cuerpos legislativos deben ser entendidos como desarrollo de la voluntad de Dios que se expresa en el Decálogo. En Dt 5, con todo, el esquema es más coherente que Ex 19-20. En efecto, en Dt 5, 24-27 el pueblo responde abiertamente que
Desde el punto de vista estilístico, el momento escénico queda bien encuadrado:

- En el v.18 se alude al temor del pueblo ante los truenos, rayos y otros fenómenos que acompañan la teofanía. En esa descripción se puntualiza la posición del pueblo con la frase "El pueblo temblando se mantenía a distancia”. Se la repetirá casi exactamente en el v.21, encuadrando el relato.

- En los vv.19-20 se trasmite el diálogo entre el pueblo y Moisés.

- En el v.21, finalmente, se narra la entrada de Moisés en la densa nube y se repite la ubicación de los israelitas en ese trance con la frase "El pueblo temblando se mantenía a distancia”, que hace de marco inferior del momento escénico.

El núcleo del momento escénico, por tanto, es el diálogo que entabla el pueblo con Moisés. Ante el temor que les infunden los elementos de la naturaleza que acompañan la manifestación divina: truenos, relámpagos y el sonido de

pondrán por obra los mandamientos que Dios les prescriba a través de la mediación de Moisés, el temor a la muerte ante la comunicación directa con Dios (el fuego) es importante pero queda en segundo plano. De hecho, el Señor alaba y aprueba la reacción del pueblo (Dt 5, 28-31). 
la trompeta, los israelitas piden a Moisés que él hable con ellos para que le puedan entender, pero que no sea Dios quien lo haga directamente pues temen morir ${ }^{44}$. Esta petición se refiere claramente a Ex 19, 19, donde el pueblo percibe la conversación entre Dios y Moisés, este habla y aquel le responde "con un trueno" 45 , también puede traducirse "con una voz". Este es el fenómeno complejo que el pueblo percibía -literalmente veía- ${ }^{46}$ en aquella circunstancia. La respuesta de Moisés no se deja esperar. Les arguye que Dios ha venido por dos motivos: para ponerlos a prueba $y$ para infundirles su temor a fin de que no pecaran. Esta respuesta supone la aceptación de la petición por parte de Moisés, toda vez que en el v.21 se narra que "El pueblo se mantenía a distancia mientras Moisés se acercaba a la densa nube donde Dios estaba" ${ }^{47}$. En Ex 19, 9a, el Señor había anunciado a Moisés el propósito de la teofanía: "para que el pueblo me oiga hablar contigo, y así te dé crédito para siempre". Ahora, en 20, 1821 se describe el primer cumpli-

${ }^{44}$ Cf. v. 19.

45 En hebreo: büqôl.

46 ver = percibir: Gn 1, 10, 12; Ex 3, 4; 8, 11 cf. BDB, 907.

47 Un sinónimo de la palabra usada en 19 , 9a.16. miento de aquel anuncio ${ }^{48}$. No se relata el asentimiento del pueblo para con Moisés como en Ex 4, 31 y/o en Ex 14, 31, sino solo el acto positivo por el cual los israelitas lo constituyen su intermediario. Ellos dejan entrever sus motivos, no entienden lo que Dios habla con Moisés ${ }^{49}$ y temen morir al hablar directamente con Dios. La aceptación de Moisés (y menos nítidamente también la de $\operatorname{Dios}^{50}$ ) al requerimiento, se describe plásticamente en el v.21 con la introducción de Moisés en el nubarrón, precedida de su discurso donde insta al pueblo, por un lado, a no temer (a la muerte) y, por otro, a ser fiel, es decir, a abrigar temor de Dios.

Pongamos algunas necesarias y breves notas diacrónicas. El relato ha sido considerado por la mayoría de los estudiosos como continuación de Ex 19, 9-19 por las siguientes razones:

- No hace referencia al Decálogo recién comunicado directamente por Dios al pueblo.

- Reanudación de la situación descrita en Ex 19, 16-19 con la alusión al temor de los israelitas

\footnotetext{
48 Cf. Ex 24, 7 donde se narra el definitivo.

49 Cf. Dt 5, 24-27.

50 Cf. Dt $5,28 s s$
} 
y a los fenómenos telúricos que acompañaban a la teofanía.

- El uso del apelativo Elohim (Dios) tal como en Ex 19, 19, sobre todo en boca de Moisés en el v.20. Este apelativo contrasta notoriamente con Ex 20, 2 , donde para introducir el Decálogo, Dios mismo se autodenomina «Yo, el Señor ${ }^{51}$, soy tu Dios». Por esta razón, los cultores de la Hipótesis documental clásica clasificaban Ex 20, 18-21 como perteneciente al supuesto documento E (Elohista).

Sin embargo, el uso de Elohim en Ex 20,18-21 podría seguir a Ex 20, 1, donde se dice que "Dios (Elohim) pronunció todas estas palabras", las cuales designarían la conversación entre Dios y Moisés descrita en Ex 19, 19. En efecto, Moisés sería el destinatario de "estas palabras", quien estaría conduciendo al pueblo al encuentro con Dios, como se afirma en Ex 19, 17. En ese trance, el pueblo percibía ese diálogo, aunque no entendía su contenido, en concreto el Decálogo ${ }^{52}$.

51 Traduce el tetragrama: YHWH.

52 El Decálogo se puede entender así como una información dada solo al lector, quien se entera en qué consisten las normas fundamentales puestas por el Señor. Los personajes de la escena morirán sin conocerlas, salvo
- Sea como fuere, la inserción de Ex $19,20-25^{53}$ y la falta de des-

escasas excepciones. Serán sus hijos quienes las conocerán en el último día de la vida de Moisés, cuando el mediador exhortando a cumplir la Segunda Ley retome estos hechos y exponga claramente el contenido del cuerpo legal fundamental de Israel. El problema de esta teoría es la incongruencia entre la ignorancia del Decálogo y la mediación de Moisés del Código de la Alianza, que en los relatos sucesivos Moisés recibirá del Señor y comunicará fielmente a los israelitas. Pero no solo eso, lo pondrá por escrito, según narra Ex 24, 4, y lo leerá frente a toda la comunidad reunida a los pies del monte Sinaí, precisamente en el acto solemne de la sanción de la Alianza, como dice expresamente Ex 24, 7. Volviendo sobre la incongruencia: ¿Cómo Israel pudo no conocer la ley fundamental por incapacidad de comprender y por temor? Encontramos una solución plausible al considerar que el no conocimiento del Decálogo por los motivos recién esgrimidos es lo que el redactor final sugiere con la disposición actual de los elementos del relato. Y, por lo mismo, Moisés lo habría dado a conocer al pueblo complementado con el resto de las normas que Dios le comunicará enseguida en la cima del monte (Ex 20, 22-23, 33; cf. Dt 6, 1ss.). Cf. C. Dohmen, Exodus, 101-102.

53 Cf. E. Buum, Studien zur Komposition des Pentateuch, BZAW 189, Berlin - New York 1990, 48-49. En contra C. Dohmen, Exodus 19-40, HThKAT, Freiburg - Basel -Wien 2004, 75-76 pues sostiene que 19, 23-24 establecen tres círculos de relación la montaña: al centro Moisés, fuera del 
tinatario de Ex 20, 1, hacen difícil que Ex 20, 18-21 pueda ser considerado continuación del Decálogo.

Las observaciones sincrónicas y diacrónicas que hemos hecho nos ayudan, ahora, a iluminar la intención teológica de esta parte del relato de la constitución de Israel como pueblo del Señor. Ya hemos recalcado bastante que con esta narración se comienza a cumplir lo que el Señor había proyectado con la teofanía narrada en Ex 19, 9-25; esto es, que el pueblo diera crédito a Moisés al verlo hablar con Dios (cf. Ex 19, 9). De hecho, los han visto charlando de un modo del todo especial, según narran Ex 19, 19 y Ex 20, 1, y se han sumido en un gran pavor, temiendo por su vida, como se afirma expresamente en Ex 20, 19b. Entonces, piden la intercesión de Moisés, quien acepta ser mediador entre Dios y el pueblo, al cual anima a no temer a la muerte, según se narra en Ex 20, 20, porque Dios ha venido con dos propósitos bien definidos:

1. Poner a prueba a Israel. Una motivación semejante a la sed experimentada por el pueblo a cau-

cerco, el pueblo; entre ambos, un espacio para personas determinadas como Aarón. Este esquema se repetiría en 24,1 . Aarón sería convocado por ser el intérprete de Moisés (cf. 4, 14). sa de las aguas amargas de Mará, según se narra en Ex 15, 22-27. En efecto, al final de ese pasaje se arguye expresamente que el Señor (¿o Moisés?), después de endulzar las aguas, dio decretos y normas y puso a prueba a Israel. Un ejemplo invertido es la prueba que el pueblo pone al Señor en la fuente de Massá, como se lee en Ex 17, 1-7.

En Ex 20, 18-21 evidentemente que la prueba consiste en vencer el temor a las manifestaciones que acompañan a la voz de Dios en su conversación con Moisés ${ }^{54}$. La respuesta de los israelitas a la propuesta de Alianza que les había hecho el Señor, descrita en Ex 19, $3 \mathrm{~b}-8$, pone en evidencia la prueba a la que está sujeto el pueblo, ante las aterradoras circunstancias de la comunicación entre el Señor y Moisés. En efecto, los israelitas se habían comprometido a hacer "todo cuanto" les había dicho el Señor ${ }^{55}$. Y hasta ese momento, solo habían conocido lo dicho por el Señor por boca de Moisés ${ }^{56}$. Ahora, quieren seguir usando solo ese medio, precisamente en atención al miedo que experimentan. Por eso, le piden sea su mediador.

2. Infundir temor en el pueblo para que no peque. Con esta fina-

\footnotetext{
54 Ex 19, 19b; cf. Dt 5, 24.

55 Ex 19, 8.

56 Ex 19, 6-7.
} 
lidad se pone de manifiesto que el temor de Dios que se quiere infundir es distinto al temor a la muerte que experimentan los israelitas ante la teofanía. De hecho, Moisés los consuela: “¡No teman!” El temor de Dios persigue la evitación del pecado; esto es, se relaciona con el respeto de la persona que adecua su conducta a la voluntad de Dios. En este contexto, el querer divino no está vinculado exclusivamente al conocimiento de la Ley fundamental, el Decálogo, pues más que probablemente el pueblo no ha conocido todavía su contenido, menos aún el del resto de las leyes. Por tanto, el temor de Dios que evita el pecado, es decir, la ofensa al Señor, proviene de su presencia y manifestación y no necesariamente del conocimiento de la Ley.

Para ilustrar el significado del temor de Dios, podemos ahondar por un breve instante en Ex 1, 1521, pasaje en el cual, a su modo, se aborda el mismo tema. En el texto se describe cómo las parteras hebreas temen a Dios y, por eso, contradicen y engañan al mismísimo faraón. Ellas perciben la presencia divina no exteriormente, sino interiormente, $\mathrm{y}$ en el contexto de una decisión crucial que afecta a la vida de inocentes niños hebreos: condenados a muerte por el solo hecho de haber nacido en el seno de familias hebreas. De este modo, narrativa- mente se afirma que la conciencia moral es anterior a la Ley mosaica y que es ante todo una sindéresis que implica una cierta relación directa con Dios presente en la propia vida. Ciertamente, en Ex 20 la presencia del Señor en la vida estriba en su plena manifestación pública y comunitaria ${ }^{57}$ y, por lo mismo, el relato está lejos de Ex 1, 15-21. Con todo, ambos pasajes dejan de manifiesto que el temor de Dios es infundido en el creyente por algún género de presencia divina. En consecuencia, el temor de Dios se debe identificar con la obediencia y/o respeto de la voluntad de Dios, manifestada de modo especial en la Ley mosaica, aunque no exclusivamente en ella; y no con la emoción subjetiva de terror ${ }^{58}$.

Ahora bien, es claro que la mediación se integra en la fe del pueblo en términos de que este servicio es necesario para su gestación y desarrollo en el devenir de la historia. Esta necesidad pone de manifiesto un aspecto fundamental de la fe en la tradición judeocristiana: Dios crea el mundo y lo

57 En Dt 4, 10-14 no es tan claro que el pueblo no haya comprendido el Decálogo como en Ex 20, 19, aunque tampoco es evidente que efectivamente lo haya entendido, sobre todo a tenor de Dt 5, 27.

58 En esta conclusión casi reproducimos B. Childs, Exodus, 373, aunque matizando que no identificamos necesariamente la voluntad de Dios con la Ley mosaica. 
dirige en relación a un co-protagonista, la raza humana, con quien teje la historia y la dirige misteriosamente a su fin. La fe, por tanto, no es un asentimiento espiritual desvinculado que sustrae del mundo y de la historia, sino muy por el contrario le da al espacio y tiempo su sentido más genuino. Pero para realizar esta significación, Dios se abaja a la realidad de los seres humanos y se nos comunica como a amigos ${ }^{59}$. Y para hacerlo usa de mediadores a fin de expresar su designio salvador en palabras humanas en el aquí y ahora, aunque él siempre conserva su libertad y su trascendencia. Por eso, el rol mediador de Moisés (y de todos los demás mediadores) es en cierto sentido una plasmación de ese coprotagonismo del que hablamos más arriba. Co-laboración y/o coautoría de la historia de salvación y en el encausamiento de ella hacia su fin. Ciertamente en Ex 20, 18-21 es clara la colaboración en la configuración de la historia salvífica, pero tal vez, donde se percibe más nítidamente esta realidad, en la perícopa del Sinaí, sea en la descripción del momento culmen de la constitución de Israel como pueblo de Dios. En efecto, en la cuidada celebración de la Alianza, cuando Moisés después de leer el Código recién comunicado por

59 Cf. Ex 33, 11. el Señor y de realizar el sacrificio sobre el altar simbólicamente construido sobre doce estelas, pronuncia esas solemnes palabras que realizan lo que expresan: "Esta es la sangre de la alianza que el Señor establece con ustedes según todas estas prescripciones" ${ }^{60}$. El pueblo que se gesta no es solo la obra de Dios, sino también el fruto de la sinergia entre el Señor y los israelitas.

De la narración pasemos a la realidad religiosa y sociológica de los destinatarios de la perícopa del Sinaí. Ellos, israelitas del post-exilio, en este relato encuentran respuesta autoritativa a una necesidad vital como comunidad creyente y como nación que sobrevivió al desastre nacional. En efecto, en el 587 a. C., el imperio babilonio había acabado con el orden político y social de Jerusalén y el reino que la circundaba: la destrucción del templo, la cesación de la monarquía davídica y el destierro de buena parte de las elites de la ciudad. Al cabo de 60 años, gracias a la consolidación de la hegemonía persa de la región se produce una nueva coyuntura histórica. Los nuevos amos de ese mundo autorizan el retorno de grupos de exiliados israelitas a Palestina a partir del 538 a. C., quienes en

$60 \quad \operatorname{Ex} 24,8$. 
colaboración con algunos de los hebreos que permanecieron en la patria instauraron un nuevo Israel en torno al templo reconstruido y aglutinaron la identidad nacional sobre dos ejes: la Ley y el culto. De hecho, carecían de los parámetros ordinarios para una tal definición: el territorio y el soberano propio. Israel se define a sí mismo como el pueblo de la alianza, pero de un pacto preciso, transmitido con seguridad por quien está revestido de autoridad divina: Moisés. Este es el sentido de la teofanía y del temor infundido por ella, esto es, que todo el pueblo dé crédito a Moisés para siempre ${ }^{61}$. En consecuencia, el sentido de la afirmación rotunda de la autoridad dada por el Señor a Moisés es responder a la necesidad de subsistencia como nación de la comunidad hebrea post-exílica que carece de territorio y de rey, pero que encuentra cohesión socio-religiosa en la adhesión a una única Ley, cuyo mediador es precisamente Moisés, y en la celebración del culto renovado en el único Santuario, cuyo ordenamiento fundamental se encuentra también en aquella misma Ley.

Este nuevo orden, sin embargo, se fue consolidando en medio de otros intentos de conformación de una realidad sociopolítica hebrea

61 Cf. Ex 19, 9. en Palestina, a los que los grupos que están tras la Torá se tuvieron que sobreponer, incluso violentamente como se registra en el rollo de Esdras y Nehemías y en otros textos post-exílicos ${ }^{62}$.

Si en la perícopa del Sinaí se enfatiza que la autoridad divina de la que Moisés está revestido, es precisamente para asegurar que las comunicaciones divinas que trasmite a los israelitas y que son elementos esenciales de su constitución como pueblo son la auténtica voluntad de $\operatorname{Dios}^{63}$. En la historia esto significa que el verdadero Israel es la comunidad en torno al templo reconstruido y no, por ejemplo, Samaria. Por tanto, el énfasis en la autoridad de Moisés contesta a quienes debaten ese orden ya que adhieren a otro o lo perciben bajo el signo de la incertidumbre. No se trata de que se nieguen las tradiciones pre-exílicas, sino que

62 El retorno de los desterrados generó, sin lugar a dudas, duras tensiones entre los antiguos moradores y los recién llegados a Palestina. Textos postexílicos dan cuenta de estos conflictos: Ez 33, Esd 4-6; 9-10; Ne 9-10. Los problemas se centraban probablemente en divergencias económicas, y más en concreto, en la posesión de la tierra: Cf. B. Schramm, The Opponents of Third Isaiah, 58-64; I. Finkelstein - N.A. Silberman, The Bible Unearthed,305-308.

63 Cf. J. L. SKA, Introducción a la lectura del Pentateuco, 296-310, complementado y ampliado en A. Ferrada moreira, El nacimiento de Moisés, 135-170. 
se da al nuevo orden un marco fundacional pre-monárquico, anterior a David y Salomón, previo a Saúl e incluso a los jueces, que sin negar los principios del orden monárquico israelita antiguo ${ }^{64}$, lo relativizan poniéndolo en un horizonte anterior: la alianza entre Dios y el pueblo. Queda de manifiesto un principio de la mentalidad antigua: lo precedente es lo más importante ${ }^{65}$. Por eso en el nuevo orden de la Jerusalén postexílica, tanto los ancianos ${ }^{66}$, como los sacerdotes ${ }^{67}$, reclamaban en sus tradiciones fundacionales, ser los sucesores de Moisés en cuanto mediadores de la Ley de Dios, en base a la cual se organiza la comunidad que está tras la Torá, cuyo corazón es la Alianza, descrita en la perícopa del Sinaí.

Sin embargo, no todo queda en el plano del relato fundacional antiquísimo, que como recién dijimos no suprime sino relativiza otras tradiciones hebreas, sino también se precisan los términos del pacto consignándolos por escrito. En efecto, lo que el Señor le

\footnotetext{
${ }^{64}$ Cf. 1Sam 7, 14, por ejemplo.

65 Cf. J. L. SKa, Introducción a la lectura del Pentateuco, 225-231 la describe como la "ley de la antigüedad o de la precedencia" que es una de las características fundamentales de la literatura antigua.

66 Cf. Dt 27, 1.

${ }_{67}$ Cf. Lv 8, 1ss; 11, 1; 13, 1.
}

trasmite en el monte Sinaí, el Código de la Alianza, Moisés lo escribe en un rollo, que a su vez lee solemnemente al pueblo, como se narra en Ex 24, 4.7. Luego, además, recibe unas tablas escritas por "el dedo de Dios" ${ }^{68}$ que contienen "la ley y los preceptos" ${ }^{69}$. Lo mismo sucederá con los demás cuerpos legales y otras leyes fundamentales de Israel contenidas en el resto de los libros del Pentateuco. En consecuencia, la autoridad de Moisés se concretiza en la autoridad de la Torá, que el Israel post-exílico, la comunidad israelita agrupada en torno al templo reconstruido, ha remarcado para fundamentar su existencia y asegurar su subsistencia como nación en las particulares circunstancias históricas y sociológicas. Su corazón, con todo, es religioso, pues aquella comunidad puede seguir existiendo gracias a su identidad religiosa, sostenida y potenciada por el culto en el Santuario, sin poseer ni un territorio ni un poder político propio. Esta coyuntura histórica surte de verdadera revolución en el contexto del mundo antiguo. Así lo describe un gran historiador contemporáneo:

En el giro de pocos años, del 520 (cuando Zorobabel llega a Jerusalén pleno de esperanzas) al 515 (cuando se inaugura el

\footnotetext{
${ }_{68}$ Ex 31, 18.

69 $\operatorname{Ex~24,12.~}$
} 
templo con la celebración de la Pascua), se cumplió una verdadera y propia revolución, respecto a la milenaria tradición que en Siria-Palestina había siempre tenido el templo como un anexo del palacio real ${ }^{70}$.

Esta revolución trajo aparejado el germen de una realidad que en nuestros días llamamos secularización y también autonomía relativa del orden creado, en especial del orden político y social. La religión de Israel inoculó el término de la divinización del poder y de toda teocracia, precisamente poniendo límites de tipo religioso al ejercicio del poder. En la constitución de la Alianza esta realidad se percibe, pues es la Ley y los preceptos debidamente asumidos por el pueblo, las relaciones con el Señor y entre los miembros de la comunidad. Con mucha más claridad se percibe este rasgo de secularidad en la así llamada "ley del rey" en Dt 17, 14-20:

${ }^{14}$ Cuando entres en el país que el Señor, tu Dios, te dará, cuando lo tomes en posesión y vivas en él, si alguna vez dices: "Voy a poner un rey para que me gobierne, como todas las naciones que están a mi alrededor», ${ }^{15}$ pondrás un rey elegido por el Señor, tu Dios, que pertenezca a tu mismo pueblo. No podrás

70 M. Liverani, Oltre la Bibbia, 342. someterte a la autoridad de un extranjero, de alguien que no pertenezca a tu pueblo. ${ }^{16} \mathrm{El}$ rey no deberá tener muchos caballos ni hacer que el pueblo regrese a Egipto, con el pretexto de aumentar su caballería; porque el Señor, tu Dios, ha dicho: «No regresen nunca más por ese camino». ${ }^{17}$ Tampoco tendrá muchas mujeres, para que su corazón no se desvíe, ni acumulará oro y plata en cantidad excesiva. ${ }^{18}$ Cuando tome posesión del trono real, hará escribir en un libro, para su uso personal, una copia de esta Ley, conforme al texto que conservan los sacerdotes levitas. ${ }^{19} \mathrm{La}$ tendrá a su lado y la leerá todos los días de su vida, para que aprenda a temer al Señor, su Dios, observando todas las palabras de esta Ley y poniendo en práctica estos preceptos. ${ }^{20}$ De esa manera, no se sentirá superior a sus hermanos, y no se apartará de estos mandamientos, ni a la derecha ni a la izquierda. Así prolongarán los días de su reinado, él y sus hijos, en medio de Israel.

Estos preceptos no solo moderan el poder del rey, evitando su "faronaización"71 con los muchos

71 Ex 14, 1-15, 21 describe el poder del faraón en sus caballos, jinetes y carros armados. El Señor los arrolló en el mar, manifestando su gloria en la derrota y aniquilamiento del ejército egipcio. 
caballos, y su "salomonización"72 con muchas mujeres, sino también pone los preceptos de la Torá como límite objetivo de su potestad, que cumplirá de manera personal y, evidentemente, las hará también cumplir a sus "hermanos". Esta denominación remarca la horizontalidad entre el monarca y su pueblo, otro despunte de secularización.

La autoridad de Moisés tan remarcada en el Pentateuco es única y pervive en el tiempo en la autoridad de los "cinco quintos de la Ley". A Moisés se lo sucede pero en relación con sus escritos -de ahí que el dogma de la autoría mosaica del Pentateuco sea tan relevante para no pocas tradiciones hebreas y cristianas-. En "estas palabras" se consigna la voluntad de Dios como camino que conduce a la vida y, además, se hace presente bajo la forma de memorial las gestas liberadoras del Señor que rescató a los israelitas, los condujo y purificó por el desierto.

\section{Conclusión}

El Año de la Fe que estamos viviendo nos sitúa delante de la au-

$721 \operatorname{Re} 3,1-3 ; 11,1-13$ describen con viveza cómo Salomón, pese a su sabiduría y piedad, se dejó arrastrar por sus mujeres extranjeras, pervirtiendo la pureza del culto y poniendo en riesgo de ese modo la identidad nacional de Israel. toridad de las Sagradas Escrituras, que en la Iglesia son norma no normada de nuestra fe y vida, una autoridad que supone el revestimiento de la misma, de unos testigos que fueron puestos en duda, pero que en su posteridad lograron suscitar adhesión y vínculo vital con sus enseñanzas y normas. ¿Por qué? No por la imposición del poder, aunque no sin su concurso no pocas veces, sino por la fuerza interior humanizadora transmitida no solo por el mensaje, sino también por la experiencia vital que lo acompaña. El ejemplo de la autoridad de Moisés, concretizada en las comunicaciones transmitidas en la Torá, ilumina la condescendencia divina que actúa en medio y a través de las coyunturas históricas y es capaz de producir revoluciones que no son reductibles a meras relaciones de causa efectos sociológicos o políticos, sino que nos abren a la relación con el absolutamente Otro que nos hace experimentar su siempre constante cercanía, sin violentar nuestra realidad criatural pero sanándola y elevándola.

Esta conclusión nos pone frente a la necesaria revitalización de una auténtica hermenéutica de la $\mathrm{fe}$, en sus principios condensados en DV 11-12 y magníficamente actualizados en VD 34. Recién el viernes 12 de abril pasado, enseñaba el Papa Francisco, al res- 
pecto, que "Los textos inspirados por Dios han sido confiados a la comunidad de los creyentes, a la Iglesia de Cristo, para alimentar la fe y guiar la vida de caridad. El respeto de esta naturaleza profunda de las Escrituras condiciona la misma validez y la eficacia de la hermenéutica bíblica. Esto comporta la insuficiencia de toda interpretación subjetiva o simplemente limitada a un análisis incapaz de acoger en sí aquel sentido global que en el transcurso de los siglos ha constituido la Tradición del entero Pueblo de Dios"73.

Además de impulsarnos a desarrollar una adecuada hermenéutica bíblica, esta reflexión nos ha permitido la contemplación de la trascendencia del Señor que se acerca al mundo, a los hombres y a las mujeres en el aquí y ahora de la historia, y ha iluminado la necesidad de mediadores entre Dios y el pueblo, dotados de poder sagrado, . Sin duda, servidores de sus hermanas y hermanos. En efecto, el mundo permanece siempre distinto de Dios y dependiente de él. Por eso, el Señor precisa de "testigos fieles" no solo para revelar a la humanidad el camino que lleva a la vida, al encuentro definitivo con él, sino también para que los conduzcan por esa senda y, entre los avatares y peligros, los defiendan, sanen, conforten y den esperanza. La necesidad de mediadores es "propter nostram salutem".

73 Discurso del Santo Padre Francisco a la Plenaria de la Comisión Bíblica Internacional, 12 de abril de 2013. 